\title{
ELECTRO-HYDRAULIC PROPORTIONAL SYSTEM REAL TIME TRACKING CONTROL DEVELOPMENT BASED ON PULSE WIDTH MODULATION METHOD
}

\author{
Ezz Eldin Ibrahim*, Tarek Elnady, Mohamed Saffaa Hassan, Ibrahim Saleh \\ Military Technical College, Cairo, Egypt \\ *E-mail of corresponding author: ezzbos@gmail.com
}

\begin{abstract}
Resume
The presented work was directed to develop the dynamic performance of an electro-hydraulic proportional system (EHPS). A mathematical model of the EHPS is presented using electro- hydraulic proportional valve (EHPV) by Matlab-Simulink, which facilitates the simulation of the hydraulic behavior inside the main control unit. Experimental work is done and the closed loop system is designed using the linear variable displacement transducer sensor (LVDT). The controller of the system is an Arduino uno, which is considered as a processor of the system. The model is validated by the experimental system. The study also presents a real time tracking control method, based on pulse width modulation, by controlling the speed of the actuator to achieve the position tracking with minimum error and low transient time, by applying the constant input signal $50 \mathrm{~mm}$ the transient time was 0.9 seconds and the error $1.8 \%$.
\end{abstract}

Available online: https://doi.org/10.26552/com.C.2021.4.B336-B345

\section{Article info}

Received 17 February 2021

Accepted 15 April 2021

Online 17 September 2021

\section{Keywords:}

hydraulic control, proportional valve, electro hydraulic proportional system,

PWM control method, position tracking control

ISSN 1335-4205 (print version)

ISSN 2585-7878 (online version)

\section{Introduction}

The proportional valve is a valve, which produces a proportional output to an electronic control input, or a valve that operates by proportional solenoids instead of on-off solenoids.

It can be classified to three types; pressure control valves, flow control valves and directional control valves.

The pressure control valves are designed mainly to control the pressure while the proportional flow control valves are designed mainly to control the flow rate and the proportional directional valve is used to control both the flow direction and the flow rate.

Many studies have dealt with the proportional valve investigations. Vaughan and Gamble [1] presented a nonlinear dynamic model of a high-speed direct acting solenoid valve, the model accurately predicted both the dynamic and steady state response of the valve to voltage inputs. Simulated voltage, current and displacement results were presented, which agreed well with experimental results.

Chen et al. [2] proposed an adaptive self-tuning controller to enable a hydraulic proportional valve to achieve accurate tracking control.

The performance of the closed-loop system was very robust as the system response remained the same under various operating conditions.

Rahman et al. [3] began the first step of converting a conventional on-off solenoid into the a proportional one.
They studied the dynamic behavior of a conventional solenoid by letting the simulation depending on the linear magnetic principle, by using the simulation package SIMNON. A comparison was done between the results from simulation model and experimental work.

Niksefat and Sepehri [4] studied the development and experimental evaluation of a hydraulic force controller, using the nonlinear Quantitative Feedback Theory (QFT) design method. The designed controller was implemented on an industrial hydraulic actuator equipped with a low-cost proportional valve.

Elmer and Gamble [5] presented a generic nonlinear dynamic model of a direct-acting electro-hydraulic proportional solenoid valve. The model accurately and reliably predicted both the dynamic and steady state responses of the valve to voltage inputs. Simulated results were presented, which agreed well with experimental ones.

Dasgupta and Watton [6] studied dynamics of a proportional controlled piloted relief valve through the bond-graph simulation technique. The simulation results were also verified by the experimental results.

Chen et al. [7] studied the nonlinear model of a variable displacement axial piston pump (VDAPP) with a three-way electro-hydraulic proportional valve (EHPV), which controlled the swash plate actuators. The time response for the swash plate angle was analyzed theoretically by the simulation model, as well as experimentally and a favorable model-following 


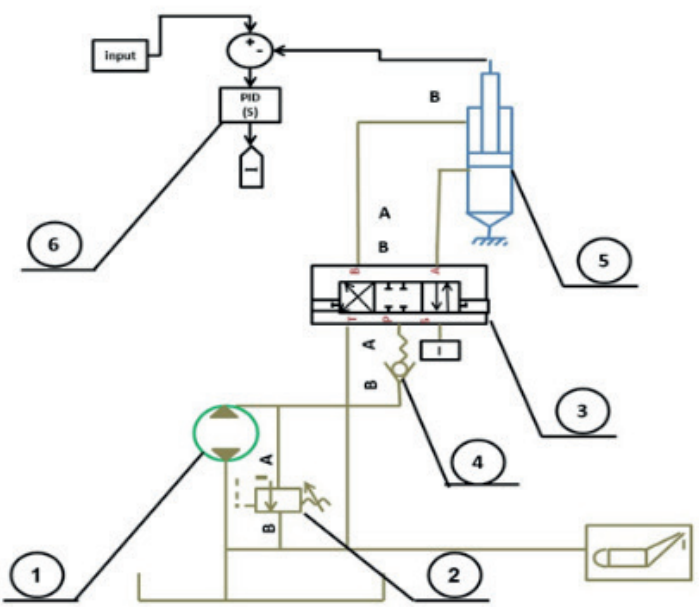

Figure 1 The EHPS hydraulic circuit

characteristics was achieved. The proposed neural controller, which conducts the nonlinear control in VDAPP, enhanced adaptability and robustness and improved the performance of the control system.

Liu et al. [8] studied an optimization of a throttle poppet valve based on hydraulic feedback principle to use it in machines. The study can be used as a guideline for design of various sizes of proportional valves.

Amirante et al. [9] designed a new methodology of spool surfaces of $4 / 3$ proportional directional valve.

It was based on redesign of both the compensation profile and spool lateral surfaces to reduce the flow forces acting on it.

The proposed methodology achieved lower actuation forces compared to the commercial configuration.

Acuna-Bravo et al. [10] presented application of a model-based control structure called Embedded Model Control (EMC).

The position tracking of the spool presented a better result by using the EMC compared to those using an industrial manufacturer.

\section{Model description}

The system shown in Figure 1 consists of hydraulic pump (1), which feed the electro hydraulic proportional valve (EHPV) (3), through the pressure relieve valve (2).

The one-way valve (4) prevents the flow to return, while the pump is in no operation mode.

The EHPV controls the output hydraulic feed delivered to the hydraulic actuator (5) to allow the hydraulic actuator tracking the required input position by the PID controller (proportional integral derivative controller) (6).

\section{Mathematical model}

The proposed system modelling is mathematically done by Matlab-Simulink and the system components configuration are selected as the same as the experimental ones.

\subsection{Hydraulic pump}

The type of the hydraulic pump used in the electrohydraulic system is a fixed displacement gear pump, which operates at nominal speed of $600 \mathrm{rpm}$ and maximum output flow rate of 6.05 liter $/ \mathrm{min}$.

The pump is driven by an $\mathrm{AC}$ electric motor that operates at 220 Volts, $50 \mathrm{~Hz}$ and $1.5 \mathrm{Kw}$.

\subsection{Relief valve}

The relief valve is used to control the pressure in the hydraulic systems to protect its individual elements, pipes and hoses from the over-pressure problems; it is adjusted at a pressure of 60 bar.

\subsection{Proportional directional valve}

The 4/3 electro-hydraulic proportional directional valve, Figure 2, is a Hydraulic Ring manufactured as type NG6. It has maximum operating pressure of 315 bar, its valve spool has zero overlap and its motion is controlled by the two electrical proportional solenoids.

\subsection{Hydraulic actuator}

The hydraulic actuator used in this study is a double acting steel, with a cam for operating the limit switch.

It has a diameter of $32 / 22 \mathrm{~mm}$, area ratio $1.6: 1$ and max pressure of 160 bar.

Figure 3 illustrates the flow through the proportional valve, were $(\mathrm{P})$ is the valve pressure port, $(\mathrm{T})$ is the valve return to the tank, (A) and (B) are the valve outputs to 


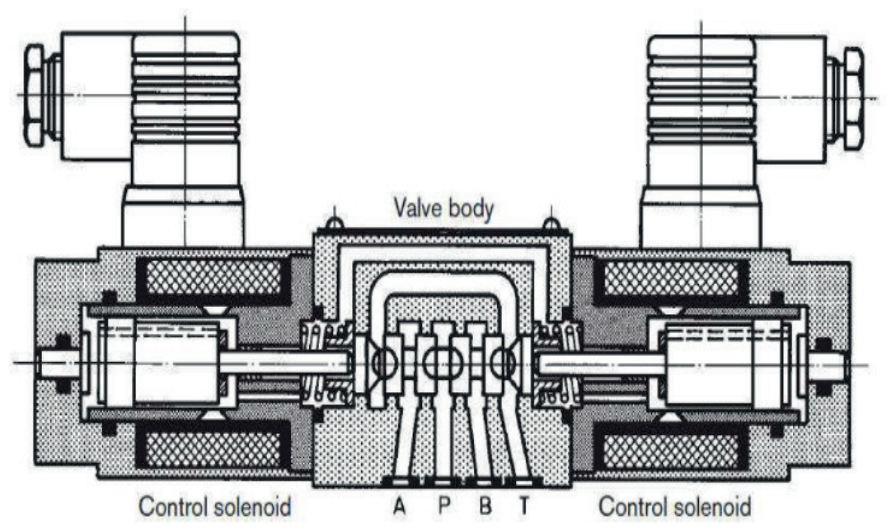

Figure 2 Typical electrohydraulic proportional valve

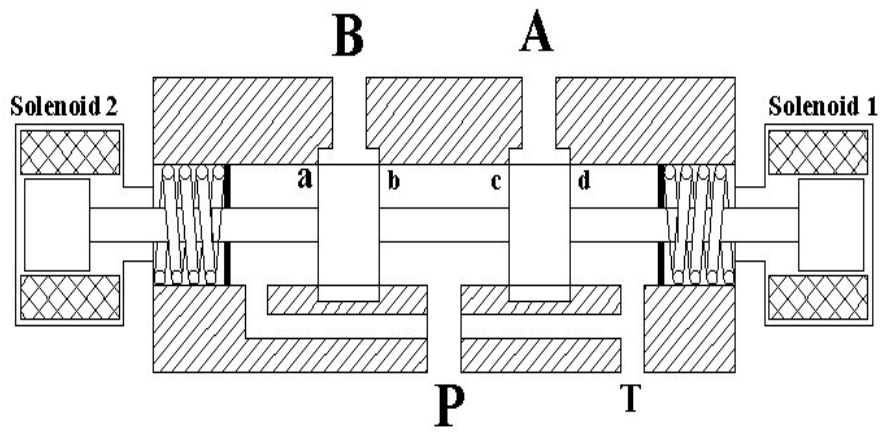

Figure 3 Proportional directional valve Internal orifices

the actuator; while $a, b, c$ and $d$ are the areas where the flow is subjected through the valve.

\subsection{Model equations}

The $Q-P$ mathematical relation of the pump has been found as following:

$Q_{p}=Q_{t h}-\left(7 \times 10^{-13} P_{p}\right)$,

where:

$Q_{t h}$ : maximum theoretical flow rate of the gear pump = 6.05 liter/min,

$P_{p}$ : pump output pressure.

The equation of poppet motion of the relief valve is:

$m_{p} \frac{d^{2} z}{d t^{2}}+f_{r} \frac{d z}{d t}+k_{r}\left(z+z_{0}\right)=p \cdot A_{p}+F_{\text {seat }}$,

$F_{\text {seat }}=K \cdot z_{0}$

The flow rate equation is:

$Q_{r v}=C_{d} A \sqrt{\frac{2\left(P-P_{t}\right)}{\rho}}$.

Equation of motion of the valve spool is:

$F_{s}=m_{s} \frac{d^{2} x}{d t^{2}}+f_{s} \frac{d x}{d t}+k x$

where: $m_{\mathrm{s}}=$ mass of spool +0.5 (mass of the return spring) $=0.021 \mathrm{Kg}$, mass of spool $=19.58 \mathrm{Kg}$ [measured], mass of spring $=1.972 \mathrm{Kg}$ [measured], $f_{\mathrm{s}}=50: 100 \mathrm{~N} . \mathrm{s} / \mathrm{m}$,

$k=24500 \mathrm{~N} / \mathrm{m}$ [measured experimentally].

Flow rate equations through the proportional valve are:

$Q_{a}=C_{d} A_{a}(x) \sqrt{\frac{2\left(P_{B}-P_{s}\right)}{\rho}}$,

$Q_{b}=C_{d} A_{b}(x) \sqrt{\frac{2\left(P_{s}-P_{B}\right)}{\rho}}$,

$Q_{c}=C_{d} A_{c}(x) \sqrt{\frac{2\left(P_{s}-P_{A}\right)}{\rho}}$,

$Q_{d}=C_{d} A_{d}(x) \sqrt{\frac{2\left(P_{A}-P_{t}\right)}{\rho}}$.

Continuity equations through the hydraulic actuator are:

$Q_{A R}-a \frac{d y}{d t}-Q_{i}-Q_{e}-\frac{\left(V_{R}+a y\right)}{B} \frac{d p_{R}}{d t}=0$,

$A \frac{d y}{d t}+Q_{i}-Q_{p s B}-\frac{\left(V_{p s}-A y\right)}{B} \frac{d p_{R}}{d t}=0$.

Actuator's equation of motion is:

$a \cdot p_{R}-A \cdot p_{p s}=m_{c} \frac{d^{2} y}{d t^{2}}+f_{c} \frac{d y}{d t}+F$.

These equations are modelled in Matlab-Simulink 


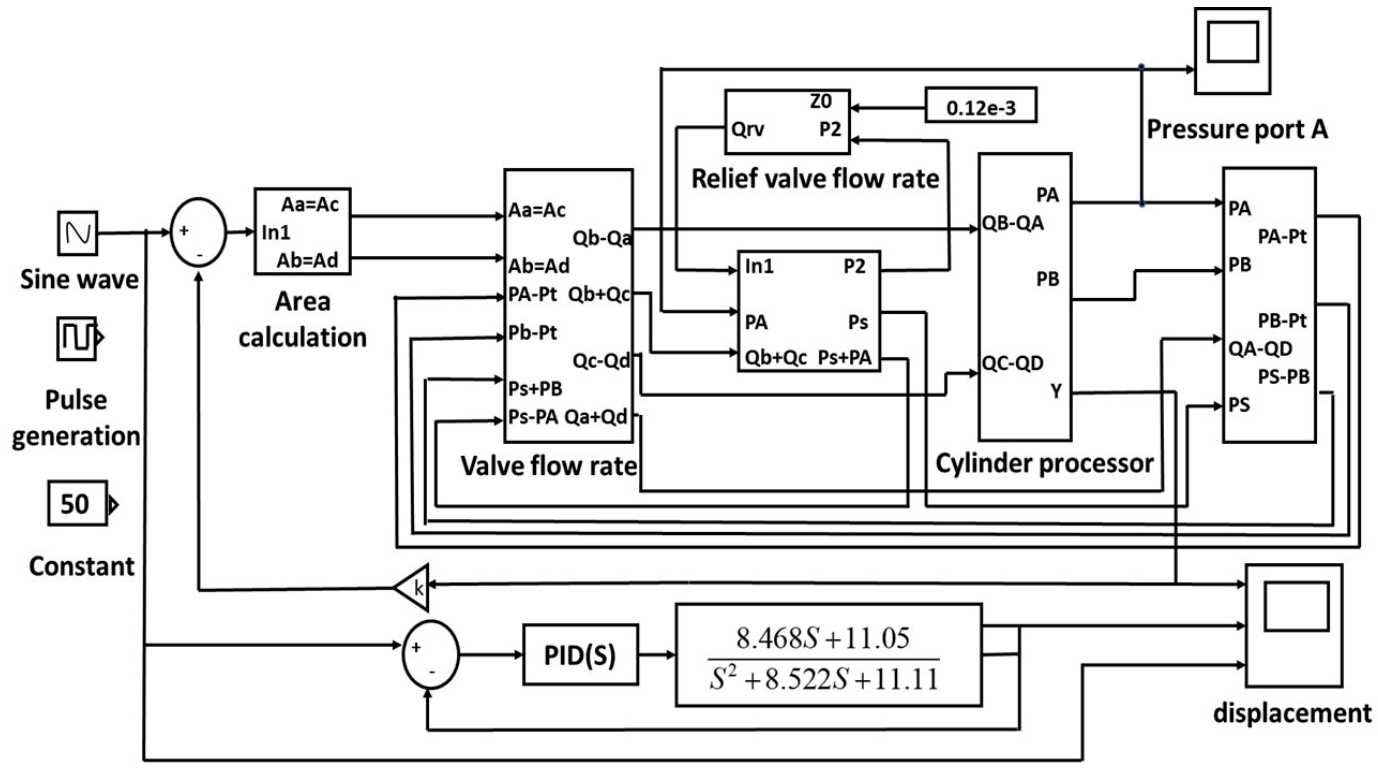

Figure 4 The EHPS mathematical model code

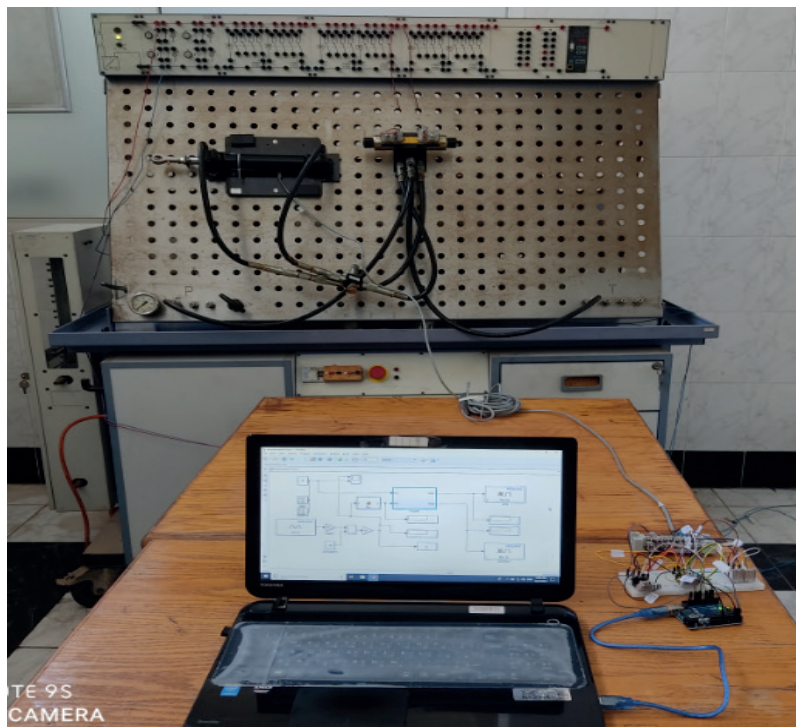

Figure 5 Electrohydraulic test rig

to facilitate the study of the fluid behavior through the hydraulic circuit and a controller is designed by the aim of Simulink tool, as well.

Figure 4 shows the simulation code of the system on Matlab-Simulink.

The system equations are represented in the code with different input signals.

The system is also represented by a transfer function, by using the system identification tool of the program and it gives the following transfer function:

$\frac{8.468 S+11.05}{S^{2}+8.522 S+11.11}$

The controller of the model can be selected, by the transfer function which is the PID controller that is used to adjust and resolve the error of the system.

It controls the system by evaluating the feedback and compensating the system error. The mathematical equation of the PID controller is:

$$
u(t)=K_{p} e(t)+K_{i} \int_{0}^{t} e(t) d t+K_{d} \frac{d e(t)}{d t},
$$

where:

$u(t)$ is the controller output, $e(t)$ is the system error,

$K_{p}, K_{i}$ and $K_{d}$ are the controller constants were: $K_{p}=0.428, K_{i}=5.58$ and $K_{d}=0$

\section{Experimental work}

The experimental work was done by using the same components configuration as mentioned in section (3), which is the same as the mathematical model configurations.

Figure 5 shows the test rig used in this study. 


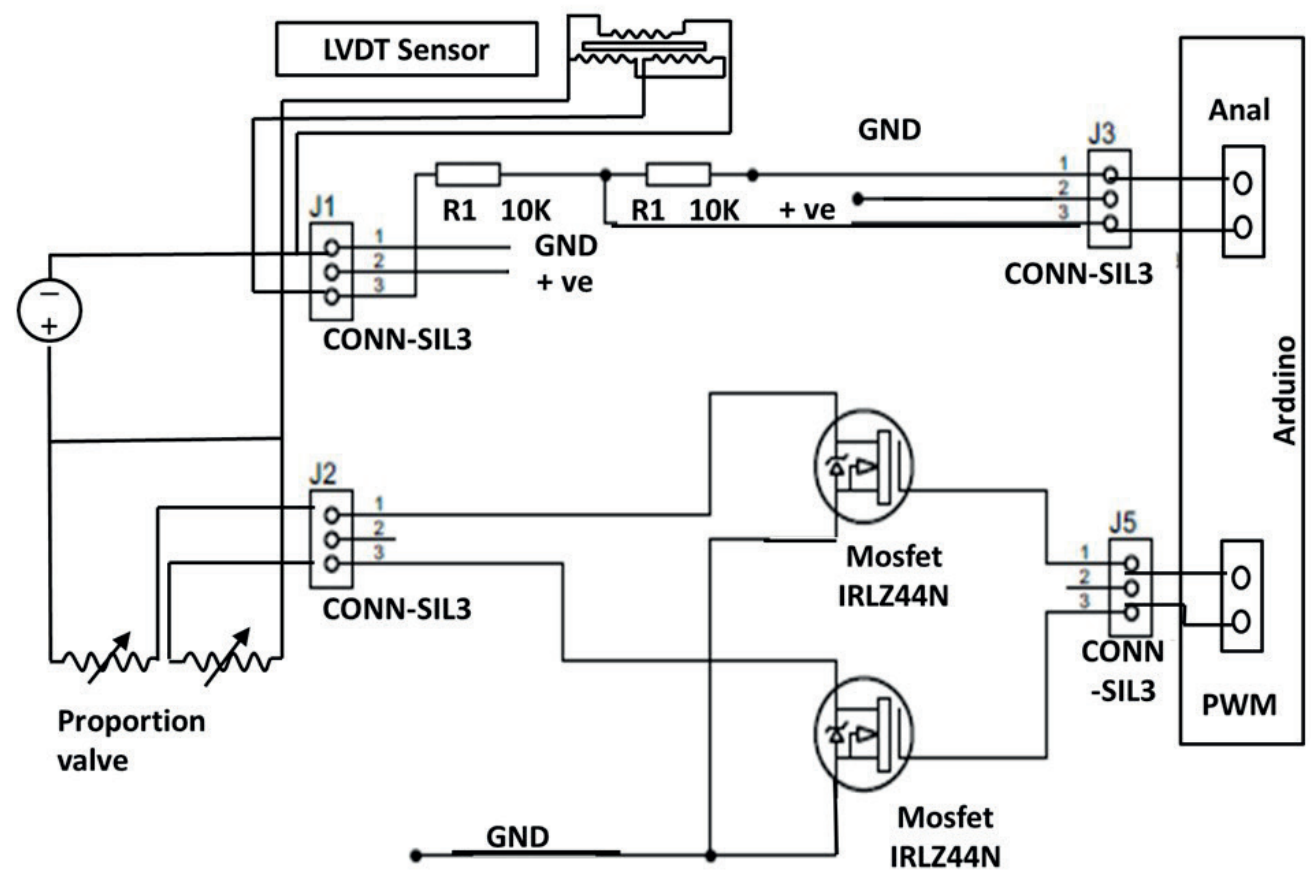

Figure 6 Electric circuit for controlling the system

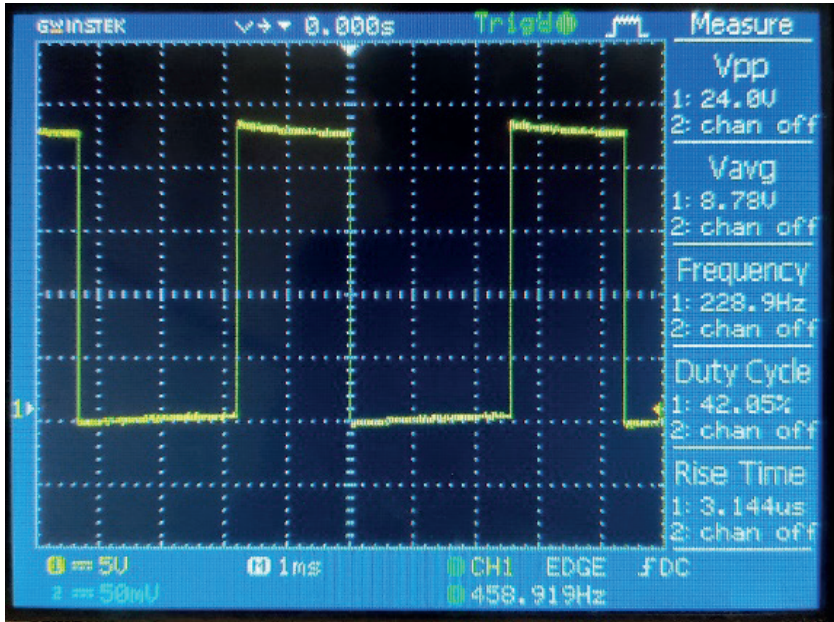

Figure 7 Pulse width modulation input signal 180

Figure 6 shows the electrical circuit used in controlling and monitoring the position tracking of the actuator.

The input signal is transferred from the MatlabSimulink to the control card (Arduino mega 2560) and then delivered to the two coils of the (EHPV) through an electric circuit.

The two coils receive the signal from the Arduino (limit voltage $5 \mathrm{~V} \mathrm{DC}$ ) and boost this signal to (24 V DC) by the aim of MOSFET transistor (IRLZ44).

The feedback position is delivered to the Arduino by displacement sensor (LVDT).

The output from the sensor is up to $(10 \mathrm{~V} \mathrm{DC})$, while, as mentioned, the Arduino limit voltage is 5 V DC.
There are a two $10 \Omega$ resistors, used in series, to reduce the limitation of the signal voltage to $5 \mathrm{~V}$ DC.

A new method of controlling the system is proposed in this study by experimentally testing the system by means of oscilloscope connecting to the two terminals of the proportional valve.

It has been found that the actuator response depends on changing the pulse width modulation (PWM).

Figure 7 shows the PWM input signal, which is detected by the oscilloscope with pulse width of 180 , as an example of the input PWM signal.

Figure 8 shows the four PWM inputs to the system and its response on the actuator position with time.

As the pulse width increases, the speed of the actuator increases, as well. 


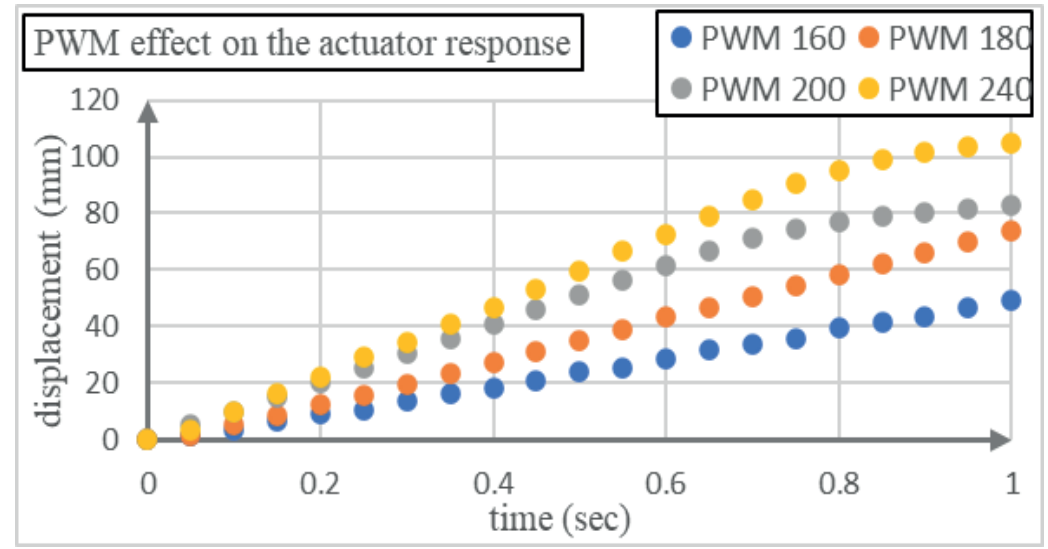

Figure 8 Effect of the pulse width modulation on actuator speed

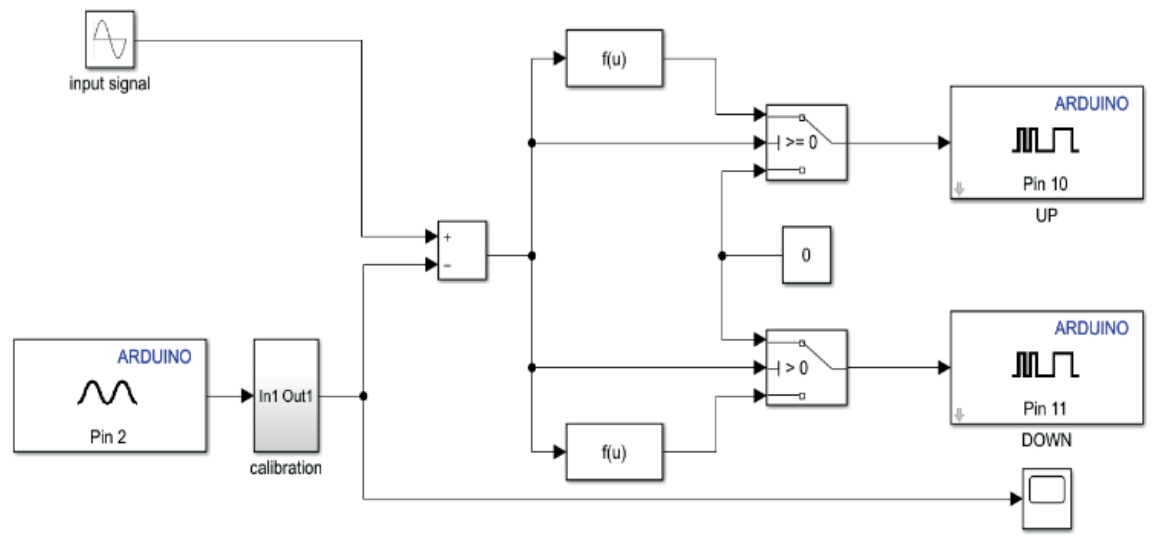

Figure 9 The EHPS controlling code

When the PWM is 160 the speed of the actuator reaches $50 \mathrm{~mm} / \mathrm{s}$ and when the PWM reaches 180 the speed of the actuator reaches $74 \mathrm{~mm} / \mathrm{s}$.

The maximum actuator speed is reached when the PWM reaches 240 as the speed reaches $105 \mathrm{~mm} / \mathrm{sec}$ and the inertia of the actuator increases, as well, which negatively affects the system control.

This experiment helps to produce a new method of electro-hydraulic proportional system control, by controlling the speed of the actuator to avoid the inertia of the actuator.

The following controller depends on adjusting the speed; when the actuator position is far from the target position the input PWM signal should be high to increase the speed of the actuator.

When the actuator approaches its target, the PWM signal should be reduced to avoid the actuator inertia.

Figure 9 shows the Matlab-Simulink code of this controller, which consists of:

- Arduino pin (2) block that receives the displacement of the actuator from Arduino, which receives it from the displacement sensor (LVDT).

- Arduino pin (10) and (11) blocks, which send the required (PWM) signal to the Arduino that delivered this signal to the two coils of the proportional valve.

- The two function blocks control the speed by calculating the difference between the input signal and the actuator position.

\section{Results and discussion}

The mathematical model is validated by the experimental work by varying the input signal with the following:

- Constant input $50 \mathrm{~mm}$, step input $70 \mathrm{~mm}$.

- Square signal $70 \mathrm{~mm}$.

- Sinusoidal signal with amplitude $30 \mathrm{~mm}$, bias $30 \mathrm{~mm}$ and frequency $0.5 \mathrm{rad} / \mathrm{sec} .08 \mathrm{~Hz}$.

These results are shown in Figures 10 to 13, as they show that the model has a good agreement with the experimental results in the constant, step and square signal inputs, respectively

When applying a sinusoidal wave, the experimental result shows a relative delay compared to the mathematical model.

This delay is due to the controller, which reduces the actuator speed to avoid the actuator inertia that led to high overshooting; however, the mathematical model result is still in a good agreement with the experimental result.

The mathematical model helps in studying the fluid behavior inside the hydraulic circuit, which is calculated.

Figure 14 shows the pressure behavior in the hydraulic circuit by applying the constant input.

Figure 15 shows the pressure behavior by applying the sinusoidal wave, those results are serving for testing the system failure, when applying a high load or object to any component malfunction. 


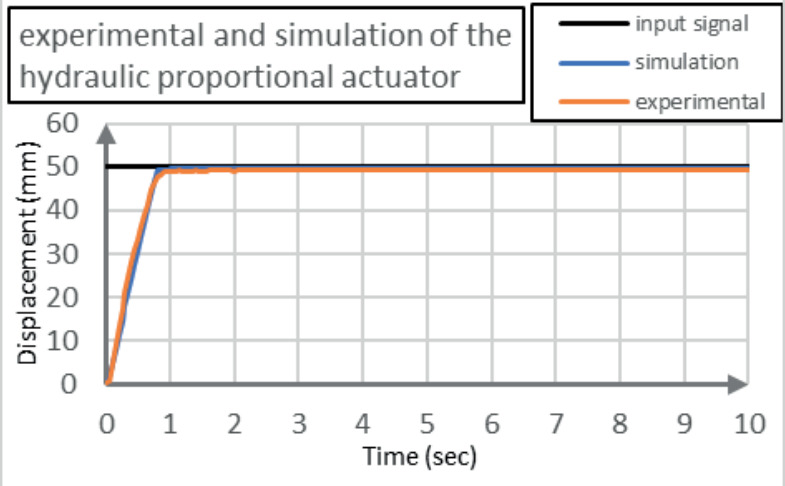

Figure 10 Hydraulic actuator response by applying the constant input of $50 \mathrm{~mm}$ (experimental vs simulation)

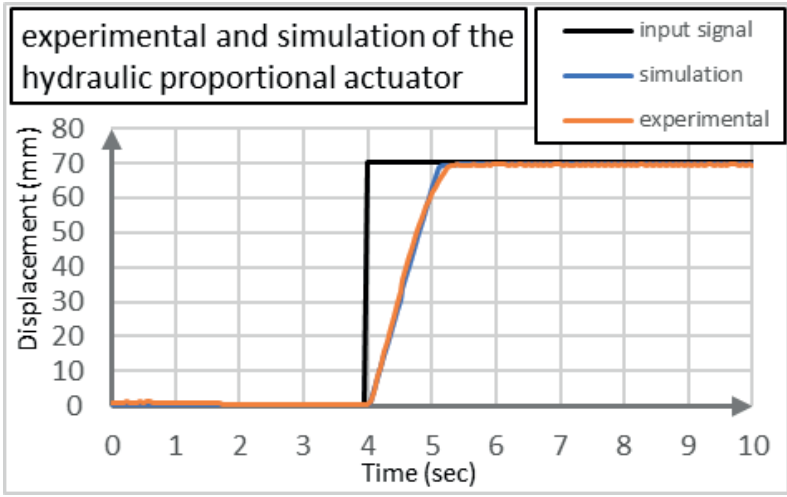

Figure 11 Hydraulic actuator response by applying the step input of $70 \mathrm{~mm}$ (experimental vs simulation)

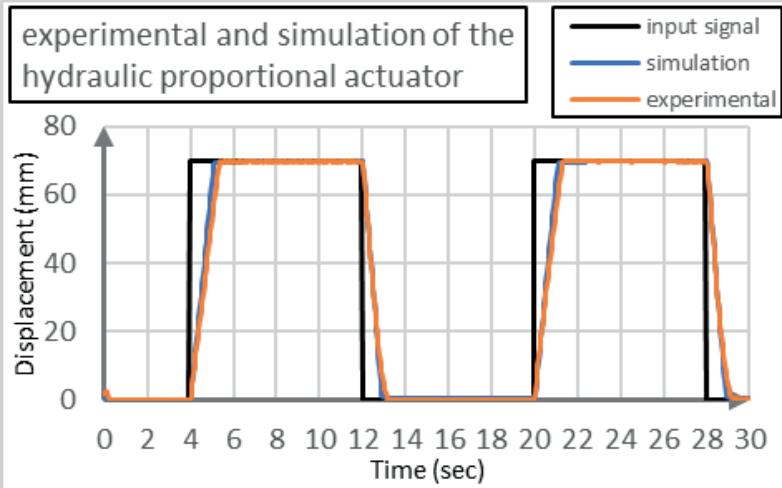

Figure 12 Hydraulic actuator response by the applying square input of $70 \mathrm{~mm}$ (experimental vs simulation)

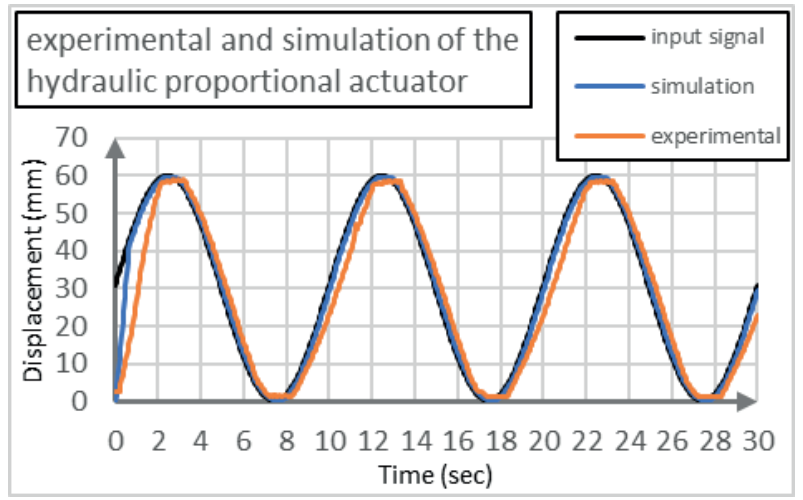

Figure 13 Hydraulic actuator response by applying the sinusoidal wave input of $30 \mathrm{~mm}$ amplitude and $30 \mathrm{~mm}$ bias with frequency) $0.08 \mathrm{HZ}$ (experimental vs simulation) 


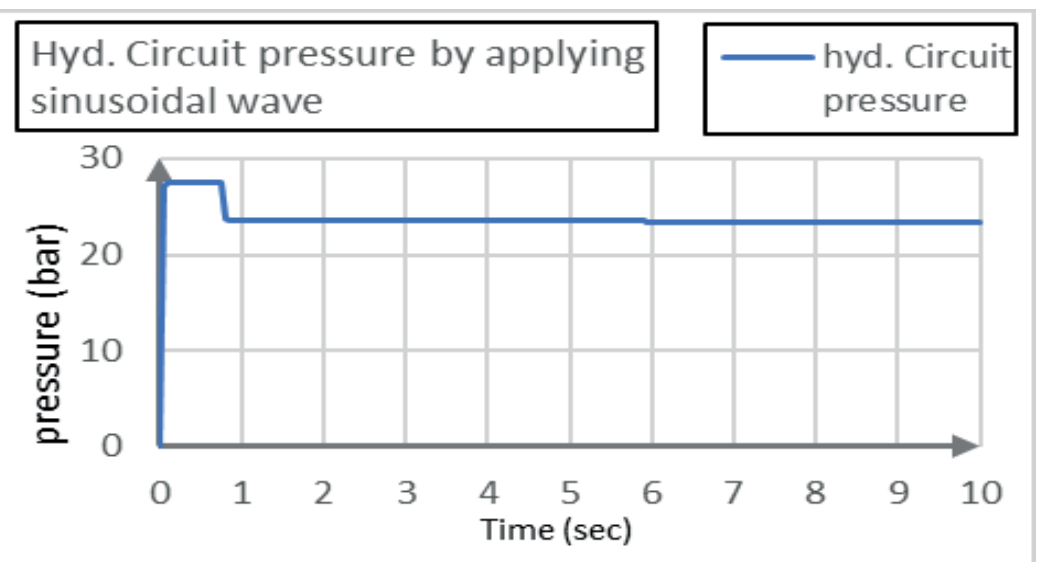

Figure 14 Hydraulic circuit pressure behavior by applying the constant input of $50 \mathrm{~mm}$

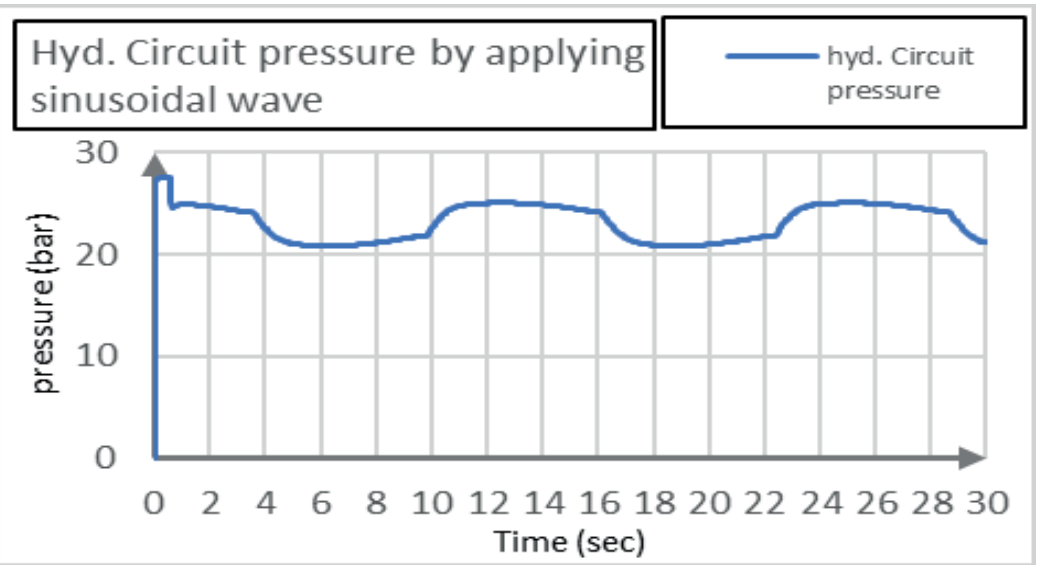

Figure 15 Hydraulic circuit pressure behavior by applying the sinusoidal wave input of $30 \mathrm{~mm}$ amplitude and $30 \mathrm{~mm}$ bias with frequency) $0.08 \mathrm{HZ}$

\section{Conclusions}

The study presented a new method for controlling the electro hydraulic proportional actuator by controlling the speed of the actuator.

This method is applied by controlling the pulse width modulation signal that operates the two coils of the proportional valve.
The proposed method of controlling the electro hydraulic proportional system is confirmed by good results with tracking different input signals.

The study presented a mathematical model of the system and its transfer function, and a controller of the model is done by the PID controller.

This study also facilitates studying the pressure behavior inside the hydraulic circuit.

\section{References}

[1] VAUGHAN, N. D., GAMBLE, J. B. The modeling and simulation of a proportional solenoid valve. Journal of Dynamic Systems, Measurement and Control [online]. 1996, 118(1), p. 120-125. ISSN 0022-0434, eISSN 15289028. Available from: https://doi.org/10.1115/1.2801131

[2] CHEN, J., DIXON, W. E., WAGNER, J. R., DAWSON, D. M. Exponential tracking control of a hydraulic proportional directional valve and cylinder via integrator backstepping. In: ASME International Mechanical Engineering Congress and Exposition IMECE’02: proceedings. 2002. p. 895-906.

[3] RAHMAN, M. F., CHEUNG, N. C., LIM, K. W. Position estimation in solenoid actuators. IEEE Transactions on Industry Applications. 1996, 32(3), p. 552-559. ISSN 0093-9994, eISSN 1939-9367. Available from: https://doi. org/10.1109/28.502166

[4] NIKSEFAT, N., SEPEHRI, N. Robust force controller design for an electro-hydraulic actuator based on nonlinear model. In: IEEE International Conference on Robotics and Automation: proceedings [online]. Vol. 1. IEEE, 1999. ISSN 1050-4729, ISBN 0-7803-5180-0, p. 200-206. Available from: https://doi.org/10.1109/robot.1999.769967 
[5] ELMER, K. F., GENTLE, C. R. A parsimonious model for the proportional control valve. Proceedings of the Institution of Mechanical Engineers, Part C: Journal of Mechanical Engineering Science [online]. 2001, 215(11), p. 1357-1363. ISSN 0954-4062, eISSN 2041-2983. Available from: https://doi.org/10.1243/0954406011524739

[6] DASGUPTA, K., WATTON, J. Dynamic analysis of proportional solenoid controlled piloted relief valve by bondgraph. Simulation Modelling Practice and Theory [online]. 2005, 13(1), p. 21-38. ISSN 1569-190X. Available from: https://doi.org/10.1016/j.simpat.2004.08.002

[7] CHEN, K., HUANG, H., RONG, Z., LIU, G., LI, Y. Model-following controller based on neural network for variable displacement pump. In: 6th International Conference on Fluid Power Transmission and Control ICFP 2005: proceedings. 2005. ISBN 7506274027, p. 28-32.

[8] LIU, W., WEI, J., FANG, J., LI, S. Hydraulic-feedback proportional valve design for construction machinery. Proceedings of the Institution of Mechanical Engineers, Part C: Journal of Mechanical Engineering Science [online]. 2015, 229(17), p. 3162-3178. ISSN 0954-4062, eISSN 2041-2983. Available from: https://doi. org/10.1177/0954406214568822

[9] AMIRANTE, R., DISTASO, E., TAMBURRANO, P. Sliding spool design for reducing the actuation forces in direct operated proportional directional valves: experimental validation. Energy Conversion and Management [online]. 2016, 119, p. 399-410. ISSN 0196-8904. Available from: https://doi.org/10.1016/j.enconman.2016.04.068

[10] ACUNA-BRAVO, W., CANUTO, E., AGOSTANI, M., BONADEI, M. Control engineering practice proportional electro-hydraulic valves: an embedded model control solution. Control Engineering Practice [online]. 2017, 62, p. 22-35, Available from: https://doi.org/10.1016/j.conengprac.2017.01.013

\section{Annex - Nomenclature}

\begin{tabular}{|c|c|}
\hline nomenclature & meaning \\
\hline a & area of cylinder rod side, $\mathrm{m}^{2}$ \\
\hline A & area of cylinder piston side, $\mathrm{m}^{2}$ \\
\hline $\mathrm{A}_{\mathrm{a}}$ & throttle area a in directional proportional valve, $\mathrm{m}^{2}$ \\
\hline$A_{b}$ & throttle area $\mathrm{b}$ in directional proportional valve, $\mathrm{m}^{2}$ \\
\hline $\mathrm{A}_{\mathrm{c}}$ & throttle area $\mathrm{c}$ in directional proportional valve, $\mathrm{m}^{2}$ \\
\hline$A_{d}$ & throttle area $\mathrm{d}$ in directional proportional valve, $\mathrm{m}^{2}$ \\
\hline$A_{p}$ & poppet area of the relief valve, $\mathrm{m}^{2}$ \\
\hline $\mathrm{B}$ & bulk modulus of elasticity of hydraulic oil, $\mathrm{N} / \mathrm{m}^{2}$ \\
\hline $\mathrm{C}_{\mathrm{d}}$ & discharge coefficient \\
\hline $\mathrm{C}$ & radial clearance, $\mathrm{m}$ \\
\hline$d$ & diameter of cylinder rod, $\mathrm{m}$ \\
\hline $\mathrm{D}$ & diameter of cylinder piston, $\mathrm{m}$ \\
\hline$F_{s}$ & proportional solenoid force, $\mathrm{N}$ \\
\hline$f_{r}$ & damping coefficient of relief valve poppet, N.s/m \\
\hline$f_{s}$ & damping coefficient of directional proportional valve spool, N.s/m \\
\hline$F_{s}$ & proportional solenoid force, $\mathrm{N}$ \\
\hline$F_{\text {seat }}$ & seat reaction of the relief valve, $\mathrm{N}$ \\
\hline$k$ & stiffness of return spring in directional proportional valve, $\mathrm{N} / \mathrm{m}$ \\
\hline$m_{p}$ & mass of poppet in the relief valve, $\mathrm{g}$ \\
\hline$m_{s}$ & mass of moving parts in the directional proportional valve, $\mathrm{kg}$ \\
\hline$p$ & pressure, bar \\
\hline$P_{A}$ & pressure at port A of the direction proportional valve, bar \\
\hline$P_{B}$ & pressure at port $B$ of the direction proportional valve, bar \\
\hline$P_{P}$ & pressure at port $\mathrm{P}$ of the direction proportional valve, bar \\
\hline$P_{t}$ & tank pressure, bar \\
\hline Q & flow rate, liter/min \\
\hline$Q_{a}$ & flow rate through opening area a at directional proportional valve block, liter/min \\
\hline$Q_{A R}$ & flow rate from port A to rod side chamber in the hydraulic cylinder, $1 / \mathrm{min}$ \\
\hline
\end{tabular}


$Q_{b} \quad$ flow rate through the opening area $\mathrm{b}$ at a directional proportional valve block, $1 / \mathrm{min}$

$Q_{c}$

$Q_{d}$

$Q_{r v}$

$V_{R}$

$V_{p s}$

$\mathrm{X}$

$\mathrm{y}$

Z flow rate through the opening area $\mathrm{c}$ at a directional proportional valve block, $1 / \mathrm{min}$

flow rate through the opening area $\mathrm{d}$ at a directional proportional valve block, $1 / \mathrm{min}$

flow rate through the relief valve, $1 / \mathrm{min}$

volume actuator rod side

volume actuator piston side

displacement of directional valve spool, $\mathrm{m}$

displacement of cylinder rod, $\mathrm{m}$

displacement of relief valve poppet, $\mathrm{m}$ 